Research Article

\title{
Minimizing the Impacts of Desertification in an Arid Region: A Case Study of the West Desert of Iraq
}

\author{
Khamis Naba Sayl $\mathbb{D}^{1},{ }^{1}$ Sadeq Oleiwi Sulaiman ${ }^{(D)},{ }^{1}$ Ammar Hatem Kamel ${ }^{D}{ }^{1}$

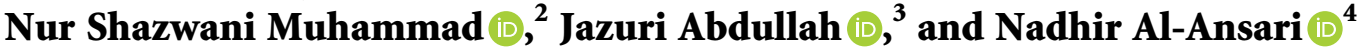 \\ ${ }^{1}$ University of Anbar, College of Engineering, Department of Dams and Water Resources Engineering, University Campus, \\ Ramadi, Anbar, Iraq \\ ${ }^{2}$ Faculty of Engineering and Built Environment, Universiti Kebangsaan Malaysia, 43600 UKM Bangi, \\ Selangor Darul Ehsan, Malaysia \\ ${ }^{3}$ Faculty of Civil Engineering, Universiti Teknologi MARA, 40450 Shah Alam, Selangor Darul Ehsan, Malaysia \\ ${ }^{4}$ Civil, Environmental and Natural Resources Engineering, Lulea University of Technology, 97187 Lulea, Sweden
}

Correspondence should be addressed to Nadhir Al-Ansari; nadhir.alansari@ltu.se

Received 22 February 2021; Revised 15 May 2021; Accepted 9 June 2021; Published 22 June 2021

Academic Editor: Yu Qian

Copyright (c) 2021 Khamis Naba Sayl et al. This is an open access article distributed under the Creative Commons Attribution License, which permits unrestricted use, distribution, and reproduction in any medium, provided the original work is properly cited.

\begin{abstract}
Currently, desertification is a major problem in the western desert of Iraq. The harsh nature, remoteness, and size of the desert make it difficult and expensive to monitor and mitigate desertification. Therefore, this study proposed a comprehensive and costeffective method, via the integration of geographic information systems (GISs) and remote sensing (RS) techniques to estimate the potential risk of desertification, to identify the most vulnerable areas and determine the most appropriate sites for rainwater conservation. Two indices, namely, the Normalized Differential Vegetation Index (NDVI) and Land Degradation Index (LDI), were used for a cadastral assessment of land degradation. The findings of the combined rainwater harvesting appropriateness map, and the maps of NDVI and LDI changes found that $65 \%$ of highly suitable land for rainwater harvesting lies in the large change and $35 \%$ lies in the small change of NDVI, and $85 \%$ of highly suitable land lies in areas with a moderate change and $12 \%$ lies in strong change of LDI. The adoption of the weighted linear combination (WLC) and Boolean methods within the GIS environment, and the analysis of NDVI with LDI changes can allow hydrologists, decision-makers, and planners to quickly determine and minimize the risk of desertification and to prioritize the determination of suitable sites for rainwater harvesting.
\end{abstract}

\section{Introduction}

With the rising expectations and needs of local citizens, developing countries are turning to greater resource development to create sustainable projects. However, desertification is a soil degradation issue that represents tremendous environmental challenges and negative impacts, especially in term of future agricultural and socioeconomic development in semiarid and arid regions, many scholars [1-3] define the desertification as the land degradation resulting from different factors, containing climatic difference and human activities in semiarid, arid, and dry subhumid areas. Climatic and physical conditions have produced widespread natural losses and cumulative soil erosion by water and wind which result in a decrease of the biological productivity of the land $[4,5]$. Desertification seems once land degradation develops irreparable or when forfeiture of total productivity extents $50 \%$ to $66 \%$ [6]. Currently, desertification is a major problem in the west desert of Iraq and leads to population displacement. A total of 4,263 families were displaced due to desertification between December 2007 and June 2009 [7]. Additionally, desertification has caused the deterioration of plants and soil covers that has harmfully affected nearly $70 \%$ of the dry land. The total area that is exposed to desertification in Iraq is estimated to be $167,000 \mathrm{~km}^{2}$, 
which is amounting to $40 \%$ of its entire area of $437,500 \mathrm{~km}^{2}[8,9]$.

Therefore, the desertification phenomenon, especially in the west desert of Iraq in the near future is irrefutable, unless effective methods and research are conducted to develop a database regarding this environmental threat. The severe nature, remoteness, and size of the desert make it difficult and expensive to understand this environmental threat. Parallel to this effort, mitigation plans can also be implemented to minimize the risk of desertification. However, this process would be limited or hindered by a lack of information. Therefore, an effective solution to mitigate the problem of desertification is needed.

One of the proposed methods for reducing the risk and impact of desertification in this study is rainwater harvesting (RWH). RWH is a significant component in any water resource system for ensuring a continuous supply, in order to meet the demand for domestic uses, livestock, agriculture, and small industries [10-13]. Moreover, the proposed rainwater harvesting system should be able to maintain a sustainable water resource and minimize the risk of further degradation of resources in the area. Four procedures are taken into consideration for sustainable RWH consisting of the selection of appropriate criteria, rating of the appropriateness of the ranking for every criterion, choosing of the locations and generation of appropriateness maps intended for the nominated sites for RWH. The process of sustainable RWH may be time-consuming and difficult when the whole of these procedures was considered particularly in large watersheds with restricted data. Geographic information systems (GISs) and geospatial data techniques are integrated to find baseline data related to droughts, desertification, and degradation, and to ease the process of attaining sustainable RWH which may directly affect agricultural development and activities in arid regions [14-16].

The combination of geospatial data with GIS approaches has guided much attention towards identifying suitable sites for RWH. The adaption of geospatial data together with GIS techniques has made it effortless to produce database concerning the hydrological potential of an area $[17,18]$. Several methods and criteria have been exercised to identify appropriate sites for RWH. Many researchers [19-23] have applied geospatial data with GIS for identifying suitable sites for RWH structures. Since water deficiency is the major problem in semiarid and arid areas, such regions would benefit from the outcomes of water managing research. Inquiries related to selecting suitable locations for $\mathrm{RWH}$ found that taking into consideration both the physical and socio-economic criteria is important for RWH.

The past studies discussed earlier required considerable data availability and accessibility to achieve their objectives. Considering the limited data availability and severity of desertification in the study area of the west desert of Iraq, the main objective of this study is to propose a comprehensive and cost-effective method for identifying and minimizing the impacts of desertification through the combination of geospatial data with GIS techniques. Rapid development in satellite image technology and GIS means that these components are easily accessible at reasonable costs. This factor is highly important, especially in areas where data are scarce or unavailable.

The aim of this study is to use the Land Degradation Index (LDI) and Normalized Differential Vegetation Index (NDVI) to estimate the potential risk of desertification, identify the most vulnerable areas, and determine the most appropriate sites for RWH. The proposed method may help decision-makers and planners for a quick reference and determination of the potential risk of desertification, as well as prioritize for determining suitable sites for $\mathrm{RWH}$ to minimize the risk of desertification.

\section{Study Area}

Wadi Al-Gahdaf is situated in the western desert of Iraq. This study area is situated to the east of the Euphrates River, between $32^{\circ} 20^{\prime} 14^{\prime \prime}$ to $33^{\circ} 08^{\prime} 00^{\prime \prime} \mathrm{N}$ and $40^{\circ} 01^{\prime} 00^{\prime \prime}$ to $43^{\circ} 30^{\prime}$ $00^{\prime \prime} \mathrm{E}$ and has a catchment area of $8513 \mathrm{~km}^{2}$ (Figure 1). The catchment experiences an arid environment with cool winters and dry summers. It is classified as a desert due to the low mean annual precipitation of between 100 and $150 \mathrm{~mm}$. About $48 \%$ of the precipitation occurs during the winter, $16 \%$ in autumn, and $36 \%$ in spring [24]. The average annual evaporation is $3300 \mathrm{~mm}$, and the monthly mean evaporation fluctuates significantly with the seasons. Considerable parts of the study area are covered with very fertile soil, in which different types of vegetation grow, such as tulips, lilies, colocynth, and numerous types of flowers grow during rainy seasons. Many drought-resistant shrubs and spiny plants are grown all over the year also covering large areas, especially in wide valleys and depressions, such as colocynth and thyme. Exposed rock outcrops of hard limestone provide a sound base for construction of barriers or dams.

The study area is considered to be a very important part of the western Iraqi desert because it represents one of main valleys that receives a significant amount of rainfall during the rainy season, and it also faces issues related to desertification. So, an effective solution to mitigate the problem of desertification is needed. An Earth dam is one technique to conserve rainwater during the rainy periods for use in dry periods, and this is considered an effective way for developing a sustainable water supply in Iraq.

\section{Data Requirements}

The data used for this study are minimal and can be divided into three major categories, that is, satellite images, meteorological data, and soil characteristics. Satellite images that include the operational land imager sensor (Landsat 8), thematic mapper sensor, and 30-meter shuttle radar topography mission (SRTM) digital elevation model were provided by the United States Geological Survey (USGS). The OLI and ETM + provide data at a spatial resolution of $30 \mathrm{~m}$ for visible, near infrared (NIR), and short-wave infrared, and of $15 \mathrm{~m}$ for panchromatic bands [25, 26]. The study area coincided with the extent of Landsat images scene (path/row: 169/037, 169/038, 170/037, 170/038, 171/037, and 171/038). A total of 6 of OLI images and 6 of Landsat 7 $\mathrm{ETM}+$ over the study area were downloaded from United 


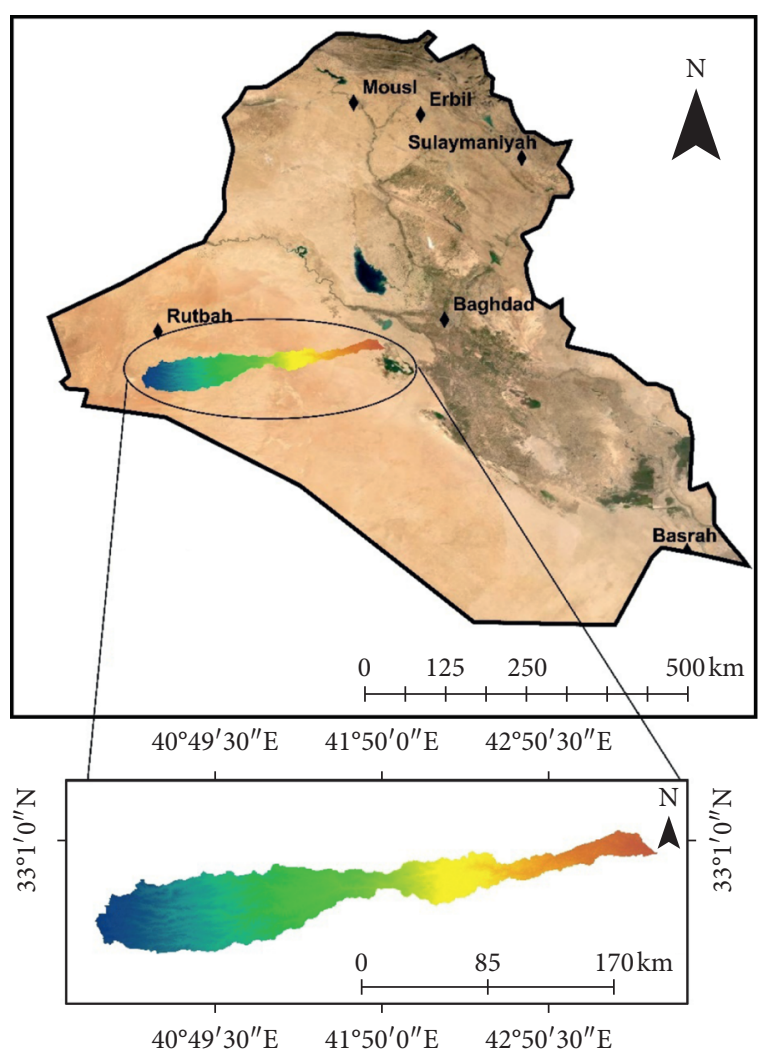

Study area DEM (m)

High: 821

Low: 15

FIGURE 1: Study area.

States Geological Survey (USGS) (https://earthexplorer.usgs. gov/). The images were acquired in dry and wet seasons. The images were geometrically and atmospherically corrected. According to UTM-WGS84 Zone $38 \mathrm{~N}$ projection, the coordinate systems of all the data used were unified. Longterm and reliable daily and monthly precipitation data of 34 years from 1980 to 2013 are also used in this study. Twentythree samples were collected throughout the study area, and the soil characteristics were determined in the laboratory. The main sources of data used in this research are presented in Table 1.

\section{Methodology}

The research methodology can be divided into two major sections: (1) an analysis of the change in the LDI and the NDVI using geospatial data in 1999 and 2014 to define the existing land degradation and (2) the determination of suitable sites for RWH to minimize the impact of desertification via Model Builder within ArcGIS 10.2. This includes the selection of suitable sites, classification of the appropriateness for every criterion, and GIS analysis for generation of suitability maps based on the combination of the weighted linear combination (WLC) and Boolean operators to order the alternative zones according to ranking with respect to evaluation criteria. The overall methodology is presented in Figure 2, while the specifics of each major section are given in the subsequent sections.

4.1. Determination of the Desertification Extent. The NDVI and LDI were used as indicators of desertification phenomenon in the study area. Thematic maps were developed for the period of 1999 to 2013, and detailed methodologies are given in the following paragraphs.

4.1.1. Normalized Difference Vegetation Index (NDVI). The application of NDVI has included the impact of various atmospheric conditions on vegetation [27-29], drought monitoring [30], identifying crop production and yield [31], and studies on desertification [32,33]. Most of these studies have been limited to quantifying the degree of desertification using NDVI. This index is an effective tool for quantifying the risk and monitoring changes of desertification as it estimates the change in vegetation according to the spectral response of the land cover $[34,35]$. The ERDAS IMAGINE software was used to determine the vegetation density changes and zones for the period of 1999 to 2013. The NDVI was estimated using the following equations [36].

From the thematic mapper sensor:

$$
\mathrm{NDVI}_{1999}=\frac{\left(B_{4}-B_{3}\right)}{\left(B_{4}+B_{3}\right)},
$$

where $B_{3}$ is the spectral reflectance value of band 3 $(0.63-0.69) \mu \mathrm{m}$, and $B_{4}$ is the spectral reflectance of band 4 $(0.77-0.90) \mu \mathrm{m}$. From the operational land imager sensor:

$$
\mathrm{NDVI}_{2013}=\frac{\left(B_{5}-B_{4}\right)}{\left(B_{5}-B_{4}\right)},
$$

where $B_{4}$ is the spectral reflectance of band $4(0.64-0.67) \mu \mathrm{m}$, and $B_{5}$ is the spectral reflectance of band $5(0.85-0.88) \mu \mathrm{m}$.

The NDVI values fluctuated between -1 and +1 . Values greater than 0 represent existing vegetation. More specifically, values between 0.0 and 0.2 represent low vegetation areas, and values of more than 0.2 represent dense vegetation areas. NDVI values between -1 and 0 represent nonvegetated areas, that is, abandoned land and urban land. The density slicing method was applied to classify the NDVI range level to estimate the effectiveness of vegetation variations between 1999 and 2013.

4.1.2. Land Degradation Index (LDI). The Land Degradation Index (LDI) reflects the condition of booths degraded land and land cover, and it has a clear physical and biological meaning [37]. The LDI is representative of the total degree of difficulty in re-educating degraded land in a specified region [38]. The LDI can be used to further enhance and demonstrate the desertification phenomenon in the study area. Many researchers $[3,39]$ have applied LDI to assess and analyze the hazards of the extension of soil degradation. The LDI was used by Meng et al. [40] to determine the degradation of soil based on band 2 and band 3 of the thematic 
TABLE 1: Summary of data used in this study.

\begin{tabular}{|c|c|c|c|c|}
\hline No. & Data type & Source & Year & Description \\
\hline 1 & $\begin{array}{l}\text { Operational land imager sensor } \\
\text { (Landsat 8) }\end{array}$ & USGS & 2014 & $\begin{array}{c}\text { Data for } 11 \text { bands in dry (August) and } \\
\text { wet (March) }\end{array}$ \\
\hline 2 & $\begin{array}{c}\text { Thematic mapper sensor } \\
\text { (Landsat7) }\end{array}$ & USGS & 1999 & $\begin{array}{l}\text { Data for } 4 \text { bands in dry (August) and wet } \\
\text { (March) seasons }\end{array}$ \\
\hline 3 & SRTM $30 \mathrm{~m}$ & USGS & 2000 & $\begin{array}{l}\text { DEM generated from SRTM, } \\
\text { UTM-WGS84 Zone } 38 \mathrm{~N}\end{array}$ \\
\hline 4 & ${ }^{1}$ Meteorological data & $\begin{array}{c}\text { Iraqi Public Authority for meteorological } \\
\text { and seismic monitoring }\end{array}$ & $1980-2013$ & Monthly and daily precipitation data \\
\hline 5 & Soil data for 23 samples & Study area & 2014 & $\begin{array}{c}\text { Physical tests were conducted in the soil } \\
\text { laboratory }\end{array}$ \\
\hline 6 & ${ }^{2}$ Tectonic map & $\begin{array}{l}\text { College of Science Anbar University- } \\
\text { Geology Department }\end{array}$ & 1999 & Location of faults \\
\hline
\end{tabular}

${ }^{1}$ Meteorological station data https://www.meteoseism.gov.iq/. ${ }^{2}$ Tectonic map College of Science Anbar University-Geology Department.

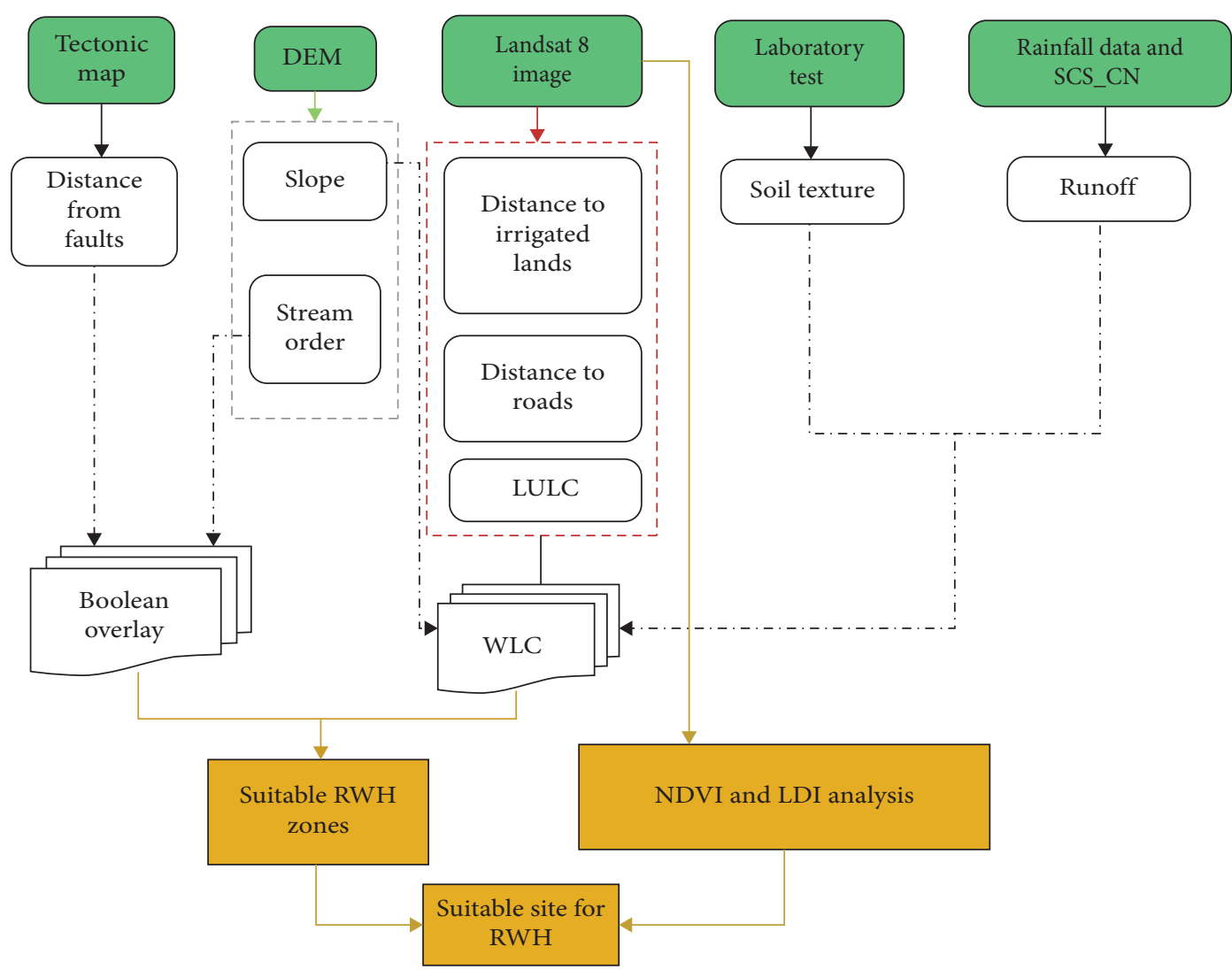

FIGURE 2: Flow chart of the overall methodology.

mapper sensor and band 3 and band 4 of the operational land imager sensor. Each of these two bands was used because they give high reflectance for soil degradation. Meng et al. [40] suggested four classes of soil degradation, namely $<30$ (extreme), (30-60) strong, (60-90) moderate, and >90 light. The estimation of LDI using the thematic mapper sensor is given as

$$
\mathrm{LDI}_{1999}=\frac{\left(255-\left(B_{2}+B_{3}\right)\right)}{\left(255+\left(B_{2}+B_{3}\right)\right)},
$$

where $B_{2}$ is the spectral reflectance of band $2(0.52-0.60) \mu \mathrm{m}$ and $B_{3}$ is the spectral reflectance of band $3(0.63-0.69) \mu \mathrm{m}$.

The estimation of LDI using the operational land imager sensor (Landsat 8) is given as

$$
\mathrm{LDI}_{2013}=\frac{\left(65,536-\left(B_{3}+B_{4}\right)\right)}{\left(65,536+\left(B_{3}+B_{4}\right)\right)},
$$

where $B_{3}$ is the spectral reflectance value of band 3 (0.53-0.59) $\mu \mathrm{m}$ and $B_{4}$ is the spectral reflectance of band 4 (0.64-0.67) $\mu \mathrm{m}$. 
4.2. Identification of the Most Appropriate Site for RWH Structures. Different criteria and constraints directly affect the process of decision-making regarding site selection. This study offers a robust method to facilitate this process combining the WLC with the Boolean operators to order the alternative zones according to favorites with respect to evaluation criteria. These methods are the most mainly used decision judgment in GIS [41-43].

4.2.1. Weighted Linear Combination Operation. The WLC integrates the maps by assigning a normalized score to every category and gives weight to the criteria themselves [44]. The WLC technique has been done in two steps: (i) multiplying the weight of each parameter by rates of category of the same parameter and (ii) adding all the criteria layers in the raster calculator. The WLC method was adopted because of its flexibility in choosing suitable sites. Several researchers have adopted this method including [45-48]. Six criteria were considered in this study in the identification of the most suitable sites for rainwater harvesting, namely slope, rainfall and runoff, land use/cover, soil texture, remoteness from irrigated land, and remoteness from roads. The criteria are measured using a variety of scales and measurements. Each criterion was first classified individually using pixel values from 0 to 10 , as given in detail in Table 2. The least convenient were categorized as 1 , while the most suitable areas were categorized as 10 . Weights, classification, appropriateness scales, and scores are based on previous studies performed in study areas with the same nature $[45,46,49-51]$.

For each criterion, the scaled map was produced with pixel amounts ranging between 0 and 10. The combined appropriateness map was created by merging these criteria layers using the raster calculator. The appropriateness amounts were then categorized into five categories namely very low, low medium, high, and very high suitability. The six criteria that are important for selecting the potential locations for RWH are discussed in the following (Figure 3):

(1) Runoff depth: it is an essential criterion for selecting a suitable site for RWH and is utilized to evaluate the possible water supply through runoff $[20,52]$. The curve number $(\mathrm{CN})$, which is expected from the consequence of land cover and soil type on rainfall/ runoff relationship, was used to estimate the runoff depth [52-54]. These data were manipulated within GIS using the spatial analysis model to generate a digital map of runoff depth in the study area based on the following equation:

$$
Q=\frac{\left(P-I_{a}\right)^{2}}{\left(P-I_{a}\right)+S},
$$

where $Q$ represents the runoff depth (mm); $P$ is the rainfall $(\mathrm{mm}) ; S$ represents the possible maximum detention after the onset of runoff $(\mathrm{mm})$; and $I_{a}$ represents a primary abstraction $(\mathrm{mm})$ that contains all losses prior the start of infiltration, runoff, evaporation, and water interception by vegetation and is specified as $I_{a}=0.2 S$ from analysis of rainfall information for small watershed [55]. Equation (5) can therefore be expressed as

$$
Q=\frac{(P-0.2 S)^{2}}{(P+0.8 S)},
$$

where $S$ can be calculated using $\mathbf{C N}$ as

$$
S=\frac{25,400}{\mathrm{CN}}-254 \text {. }
$$

CN lies between 0 and 100, and this value signifies the runoff constrained to a specified precipitation amount. High $\mathrm{CN}$ values show that a considerable proportion of the rain will develop surface runoff [56]. The CN map and rainfall data for the study area were used to infer the layer of runoff depth in terms of the hourly extreme rainfall of the whole research area (Figure 3(a)). The minimum and maximum values of the runoff depth vary between 7 and $35 \mathrm{~mm}$, with runoff increasing in the downstream part. The first category of $<20 \mathrm{~mm}$, represents $17 \%$, the second category of $20-25 \mathrm{~mm}$ represents $22 \%$, the third category of $25-30 \mathrm{~mm}$ represents $32 \%$, the fourth category of $30-35 \mathrm{~mm}$ represents $16 \%$, and the final category of $>35 \mathrm{~mm}$ represents $13 \%$ of the entire area.

(2) Slope: the generation of runoff also greatly depends on the slope which affects the velocity of flow, the amount of sedimentation, and the quantities of construction material needed to erect the RWH structure. Critchley et al. [57] recommended that an RWH structure is not suitable for the slopes exceeding $5 \%$ because erosion rates are higher and required larger earthworks [46]. A DEM generated from SRTM data for the research area was used to generate the slope map which was categorized into five categories (Figure 3(b)): the first category of $<2 \%$, represents $9 \%$, the second category of $2 \%$ to $3 \%$ represents $9 \%$, the third category of $3 \%$ to $4 \%$ represents $10 \%$, the fourth category of $4 \%$ to $5 \%$ represents $10 \%$, and the final category of $>5 \%$ represent $62 \%$ of the entire area.

(3) Soil texture: the soil texture category is determined by the percentage of clay, silt, and sand, which affects the rate of infiltration and surface runoff. Mediumand fine-textured soils are typically more suitable for RWH due to their improved water retention. Since the low permeability of clay and its ability to retain the harvested water, sites with clay soil proved to be the best for water storage [58]. Therefore, the soil texture is a critical factor for selecting sites for RWH. A soil map was generated based on soil samples that were taken from 23 sites in the study area using an auger, with depths ranging from 20 to $40 \mathrm{~cm}$. The particle size distributions were used to classify the soil samples according to the USGS method of texture classification. The spatial analysis tool with 
TABLE 2: Weights, classification, appropriateness scales, and scores for each criterion for RWH in semiarid and arid areas [45, 46, 50, 51].

\begin{tabular}{|c|c|c|c|c|}
\hline Criteria & Weights & Class & Value & Score \\
\hline \multirow{5}{*}{ Slope (\%) } & \multirow{5}{*}{8} & Very high & $2-3$ & 9 \\
\hline & & High & $3-4$ & 8 \\
\hline & & Medium & $<2$ & 6 \\
\hline & & Low & $4-5$ & 3 \\
\hline & & Very low & $>5$ & 1 \\
\hline \multirow{5}{*}{ Runoff (mm) } & \multirow{5}{*}{9} & Very high & $>35$ & 9 \\
\hline & & High & $30-35$ & 8 \\
\hline & & Medium & $25-30$ & 7 \\
\hline & & Low & $20-25$ & 3 \\
\hline & & Very low & $7-20$ & 1 \\
\hline \multirow{5}{*}{ Land use/cover } & \multirow{5}{*}{7} & Farmed and grass & Very high & 9 \\
\hline & & Moderate & High & 7 \\
\hline & & Bare soil & Medium & 5 \\
\hline & & Mountain & Low & 1 \\
\hline & & Water body and urban area & Restricted & Restricted \\
\hline \multirow{5}{*}{ Soil texture } & \multirow{5}{*}{6} & Very high (clay) & $>20 \%$ & 9 \\
\hline & & High (silty clay) & $15-20 \%$ & 7 \\
\hline & & Medium (sandy clay) & $11-15 \%$ & 4 \\
\hline & & Low (sandy clayey, loam, and sandy loam) & $8-11 \%$ & 3 \\
\hline & & Very low (others) & $<8 \%$ & 1 \\
\hline \multirow{5}{*}{ Distance from irrigated lands } & \multirow{5}{*}{5} & Very high & 8 & 9 \\
\hline & & High & 7 & 8 \\
\hline & & Medium & 6 & 7 \\
\hline & & Low & 5 & 5 \\
\hline & & Very low & 4 & 3 \\
\hline \multirow{5}{*}{ Distance from roads } & \multirow{5}{*}{4} & Very high & 8 & 9 \\
\hline & & High & 7 & 8 \\
\hline & & Medium & 6 & 7 \\
\hline & & Low & 5 & 5 \\
\hline & & Very low & 4 & 3 \\
\hline
\end{tabular}

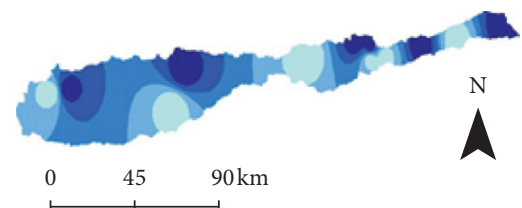

$\mathrm{mm}$

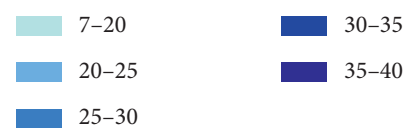

(a)
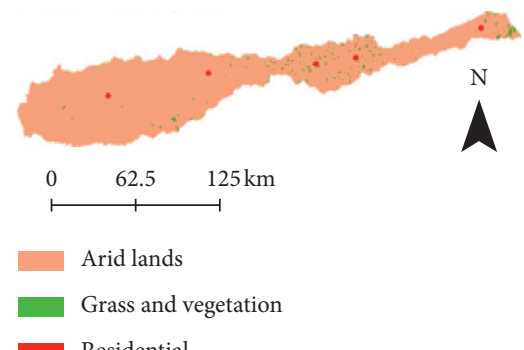

(d)
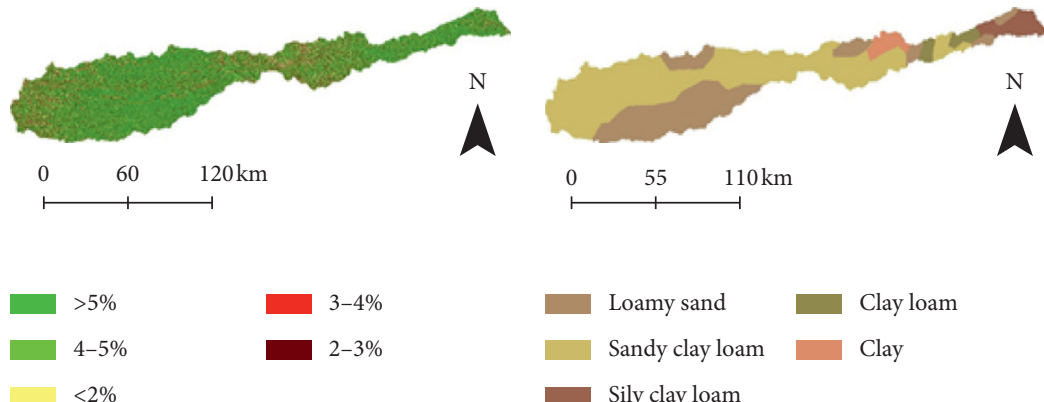

$3-4 \%$

$2-3 \%$

(b)
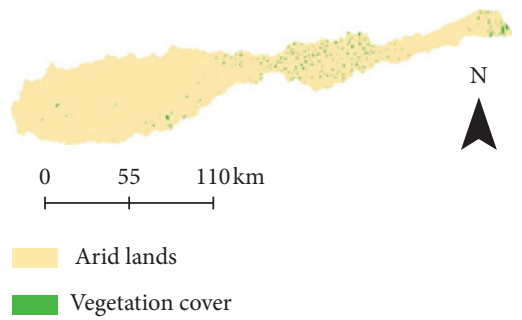

(e)

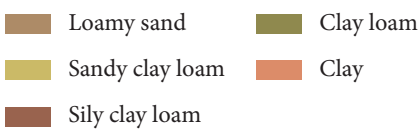

(c)
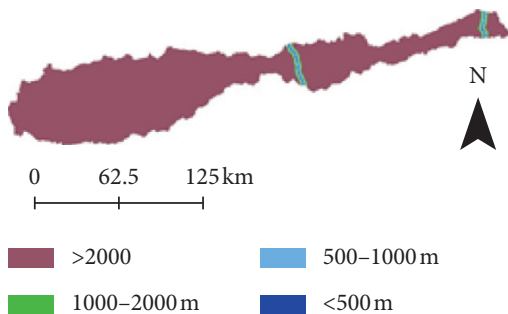

(f)

Figure 3: Weighted Linear Combination WLC criteria. (a) runoff depth; (b) slope; (c) soil texture; (d) land use land cover; (e) vegetated cover; (f) distance from the road. 
GIS platform was used to develop the soil map (Figure 3(c)). A large portion of the study area is covered by sandy clay loam, which represents fertile soil when water is available. As shown in Figure 3(c), the soil map was categorized into five classes, that is, the first category (loamy sand) represents 30\%, the second category (sandy clay loam) represents 59\%, the third category (silty clay loam) represents $5 \%$, the fourth category (clay loam) represents 3\%, and the final category (loam) represents $3 \%$ of the entire area.

(4) Land use land cover (LULC): Kahinda et al. [59] found that denser vegetation represents the higher rates of infiltration and lower runoff. The land use/ cover map was extracted from Landsat 8 satellite image taken in June 2019. The land use/cover, as a result of supervised classification, categorized the study area into three main categories consisting of: grass and vegetation (17\%), residential (2\%), and barren land (81\%) (Figure 3(d)).

(5) Distance from irrigated land: it is crucial that the RWH structure sites be close to the cultivable zone [21]. Therefore, the distance from irrigated lands was adopted in this study. The NDVI was used to identify the green area (irrigated/activity growing vegetation). A vegetation cover map was derived from Landsat 8 satellite image taken in April 2019. The vegetated cover represents $25 \%$ of the entire study area (Figure 3(e)).

(6) Distance from roads: roads have a considerable socio-economic significance for the area's population in the study region by providing access to water and grass for their livestock. The existing roads close to the suggested site contribute to reducing transportation costs. People, there may drive their trucks and tankers across these roads from one location to another. The distance from the road was categorized into four classes 250 to 500,500 to 1,000 , 1,000 to 2,000, and $>2,000 \mathrm{~m}$ (Figure $3(\mathrm{f})$ ). Less than $250 \mathrm{~m}$ did not recommend prohibiting any future inconsistency between RWH structure and roads [50]. A map of this parameter was obtained, based on the buffer areas adopted in Table 1, from Landsat 8 images taken in June 2019.

4.2.2. Boolean Overlay Operation. The Boolean overlay method separates the operation of site selection based on using either (the OR) or (the AND); it is crispy (false or true), and it is limited to a small discrete location. Many researchers $[15,60]$ have adopted this approach. The Boolean overlay approach is an important method for eliminating a specific area identified by the WLC method. The stream order and distance from faults are adopted in this method. The details of the two criteria are discussed as follows (Figure 4):

(1) Distance from faults: faults are a major hindrance when determining an RWH system. The location of faults is determined by the use of an obtainable geological map of the research area. The exclusion of the fault area from the adopted sites is critical when identifying a site for RWH [46]. Consequently, a value of 0 is given to areas that are at a distance of $1,000 \mathrm{~m}$ or less from the fault area, whilst a value of 1 is given to areas more than $1,000 \mathrm{~m}$ away (Figure 4(a)).

(2) Stream order: the stream order signifies the hierarchical linking between stream sections and allows the categorization of drainage watershed via their size. The suitability of RWH depends strongly on the wadi density, and highly dense regions are the most appropriate. Analysis of stream order is very important for site selection for RWH; a lower stream order has a higher infiltration and permeability. A stream order larger than a fourth order is given the value 1, while a stream order smaller than a third is given the value 0 in this study [52]. The thematic map of the stream order is classified as very low (2), low (3), moderate (4), high (5), and very high (6). Higher stream order (sixth) was showed in the north east part with a total length of $214.7 \mathrm{~km}$; the total length of the fifth order is $152.2 \mathrm{~km}$; the total length of the fourth order is $296.4 \mathrm{~km}$; the total length of the third order is $643 \mathrm{~km}$ (Figure 4(b)).

4.3. Development of Potential Sites for Rainwater Harvesting. To identify the possible sites for RWH, the vector and raster GIS database was establish using Model Builder in ArcGIS 10.2. After that process was completed, suitability maps were developed. The appropriate areas for RWH were determined by rescaling all layers of WLC criteria, that is, slope, rainfall and runoff, land use/cover, soil texture, distance from irrigated land, and distance from roads and combining them by spatial analyst tool with the platform of ArcGIS 10.2. Spatial analyst tools with raster calculators were used in the ArcGIS platform for the Boolean criteria, that is, stream order and distance to the faults to obtain the sites with values of 1 which were suitable for RWH. Following this, the land suitability of the combined WLC and Boolean methods was categorize based on the NDVI and LDI to determine the areas that should be considered first and that were most appropriate for RWH structures.

\section{Results and Discussion}

The application of NDVI is an effective tool for quantifying the risk and monitoring changes of desertification, which include the impact of various atmospheric conditions on vegetation, and drought monitoring. The density slicing method was used to classify the NDVI change from 1999 to 2013. The results show that the area with a significant change of NDVI is $6,981 \mathrm{~km}^{2}$, which represents $82 \%$ of the total study area, while the area with a low change of NDVI is $1,532 \mathrm{~km}^{2}$, which represents $18 \%$ of total study area. The rate of deterioration of vegetation cover reached $18 \%$ in less than 15 years. Therefore, the percentage of land classified as nonvegetation increased, and it is expected to accelerate as a 

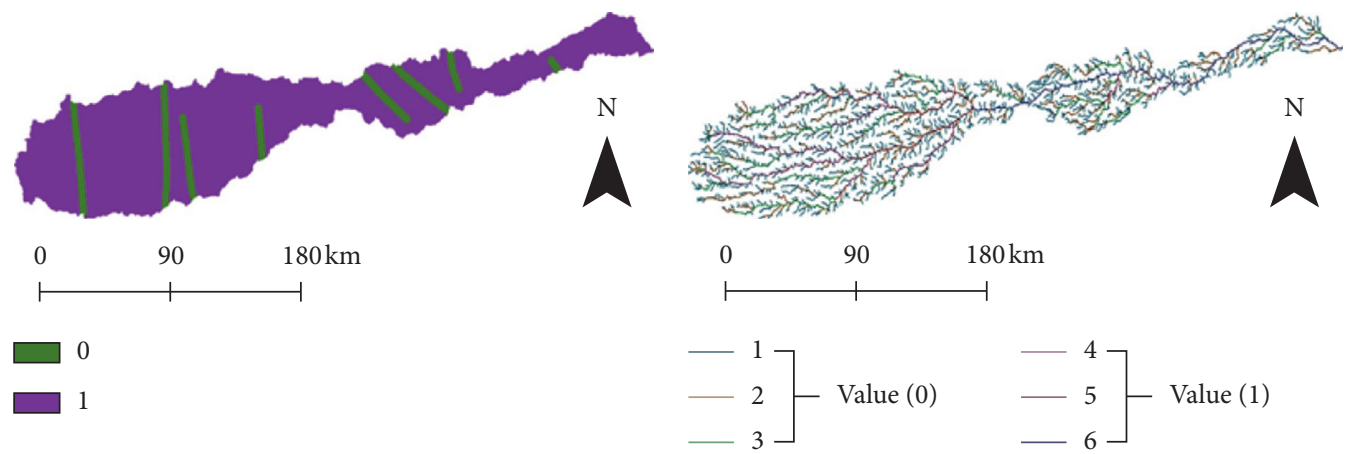

(a)

(b)

FIGURE 4: Boolean overlay criteria. (a) Distance from faults; (b) stream order classifying.

result of the desertification phenomenon in the study region (Figure 5).

Other than NDVI, LDI could also be used to further enhance and prove the desertification phenomenon in the study area. The findings of the changes in LDI were mostly classified as extreme degradation $\left(766 \mathrm{~km}^{2}\right.$, represents $\left.9 \%\right)$, strong degradation $\left(5363 \mathrm{~km}^{2}\right.$, represents $\left.63 \%\right)$, followed by moderate degradation $\left(2299 \mathrm{~km}^{2}\right.$, represents $\left.27 \%\right)$, and none degradation $\left(85 \mathrm{~km}^{2}\right.$, represents 1\%) for the period of 1999 to 2013 (Figure 6). The change in land degradation increased as a result of the desertification phenomenon in the study region.

As a result of the NDVI and LDI analysis, the percentage of land classified as nonvegetation increased, and it is expected to accelerate as a result of the desertification phenomenon in the study region. Therefore, RWH is a significant component for minimizing the risk of desertification. This study aimed to simplify the process of determining suitable sites based on a combination of the WLC method and the Boolean overlay to order the alternate zone according to favorites with respect to valuation criteria. After determining the watershed properties in the stage of GIS, the suitability sites for RWH were determined using multicriteria evaluation for six criteria, that is, the runoff depth, soil texture, slope, land use (LULC), distance from roads, and distance from irrigated lands, adopted in the WLC step. All layers of the criteria were combined in the raster calculator to gain a definitive map of the WLC criteria (Figure 7). The results map show that the maximum value calculated through the WLC way is 46 , while the minimum value is 16 . The differences between the maximum and minimum value of the WLC method can be divided into three classes. For this work in study area, the values that ranged between 36 and 46 represents suitable area (16\%), the values between 26 and 36 represents moderately suitable areas $(60 \%)$, and the values between 16 and 26 represents unsuitable areas (24\%) for the entire study area (Figure 7). The map of WLC criteria shows that the most downstream zone of the study area is suitable for RWH. The main soil texture in the suitable regions was clay, clay loam, and silty clay loam, and was intensively cultivated. Moreover, the regions suitable for RWH, had a runoff depth diversity of between 30 and $40 \mathrm{~mm}$ and slopes varied between $2 \%$ and

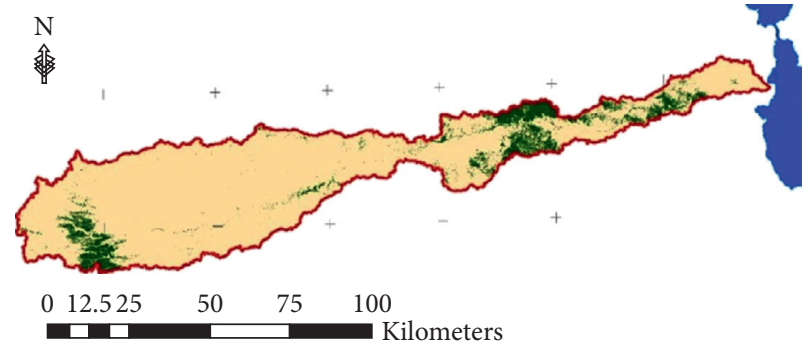

Change in NVDI Index

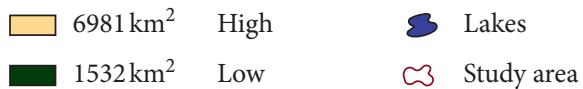

FIGURE 5: Change in the normalized vegetation difference index (NDVI) from 1999 to 2013.

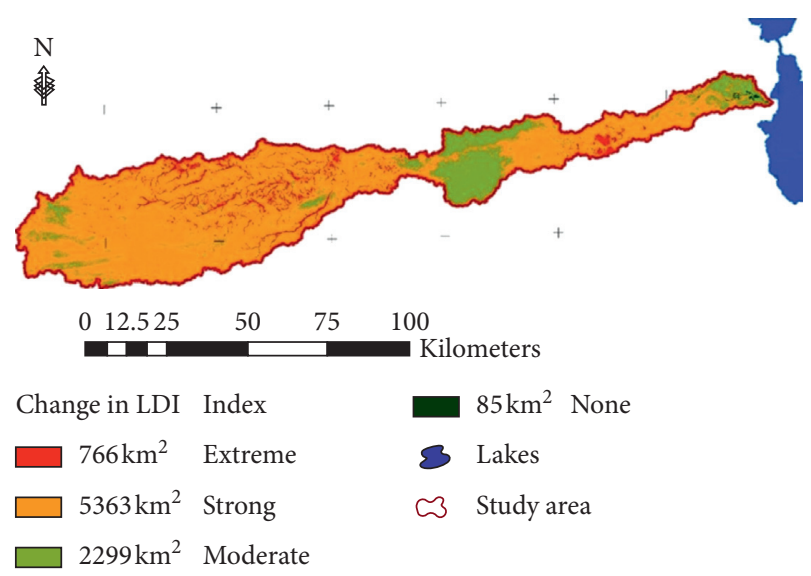

Figure 6: Change in the LDI from 1999 to 2013.

$4 \%$. The results map is in agreement with the studies of Adham et al. and Mbilinyi et al. [20, 58]. These studies demonstrated that areas with fine to moderate slopes incorporated with clay and clay loam were appropriate for RWH.

In the western desert of Iraq, the scarcity of surface water resources, and the high cost of groundwater investment because of the $200 \mathrm{~m}$ depth in some region, require special 


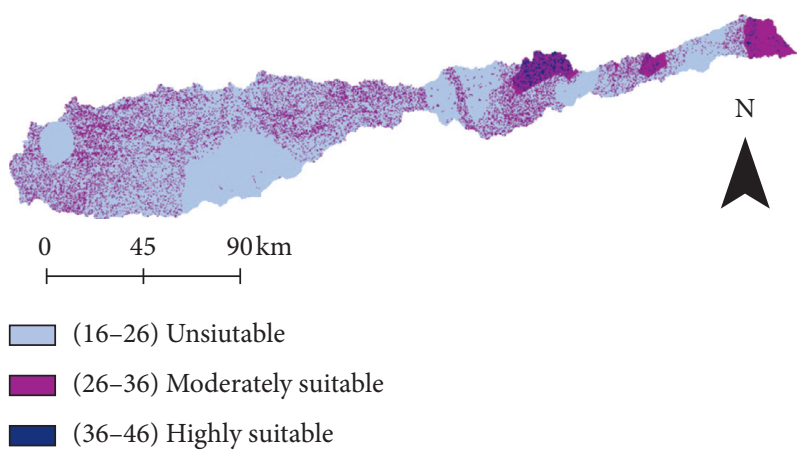

Figure 7: Outcome of WLC analysis of slope, rainfall and runoff, land use/cover, soil texture, remoteness from irrigated land, and remoteness from roads criteria.

effective water resources management $[9,21]$. An Earth dam is one method to conserve rainwater during rainy periods for usage in dry periods, and it is considered an effective way for developing a sustainable water supply in Iraq. Therefore, the Boolean overlay method was used to limit the potential sites for RWH throughout the seasonal drainage network. Based on the faults distributed in the entire study area and stream order, a finding map of the Boolean overlay was generates as shown in Figure 8. This is a significant method for excluding certain areas identified by the WLC process. The findings of Boolean overlay, for which the value 1 represents $35 \%$ and the value 0 represents $65 \%$, show that the very high potential for RWH sites represents the highest stream (sixth order), which was showed in the outlet of the catchment of the study area.

The findings map of WLC criteria, and Boolean overly criteria were multiplied to yield the concluding raster map (Figure 9). The resulting map included three units that have been used as markers for possible RWH sites due to their suitability: suitable, moderate, and unsuitable. These units meant that only $2 \%$ of the catchment is suitable, $24 \%$ of the catchment is moderately suitable, and $74 \%$ of the catchment is not appropriate.

According to the analysis of the potential sites for RWH in the catchment area with the NDVI and LDI changes, it was demonstrated that $65 \%$ of highly suitable sites are in areas with a large change of NDVI, and $35 \%$ of highly suitable sites are in areas with a small change of NDVI, while $90 \%$ of moderately suitable sites are in areas with large change of NDVI, and $10 \%$ of moderately suitable sites are in areas with a small change of NDVI, $85 \%$ of highly suitable sites are in areas with a moderate change of LDI, $12 \%$ of highly suitable sites are in areas with a large change, and only $3 \%$ of highly suitable sites are in areas with no change.

In comparison with the literature, the adaption of together the WLC and Boolean methods within the GIS environment and the analysis of NDVI with LDI changes can enable hydrologists, decision-makers, and planners to quickly determine and minimize the risk of desertification and prioritize for determining suitable sites for RWH. Moreover, this methodology can help decision-makers and planners to estimate the potential risk of desertification, identify the most vulnerable areas, and determine the most proper sites for RWH.

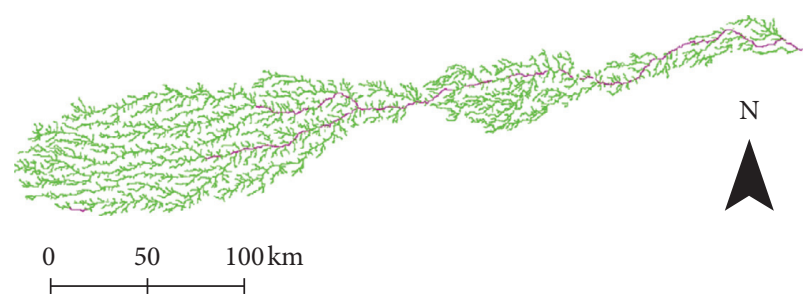

(0) Unsiutable

(1) Siutable

Figure 8: Outcomes of Boolean overlay analysis of distance from faults and stream order.

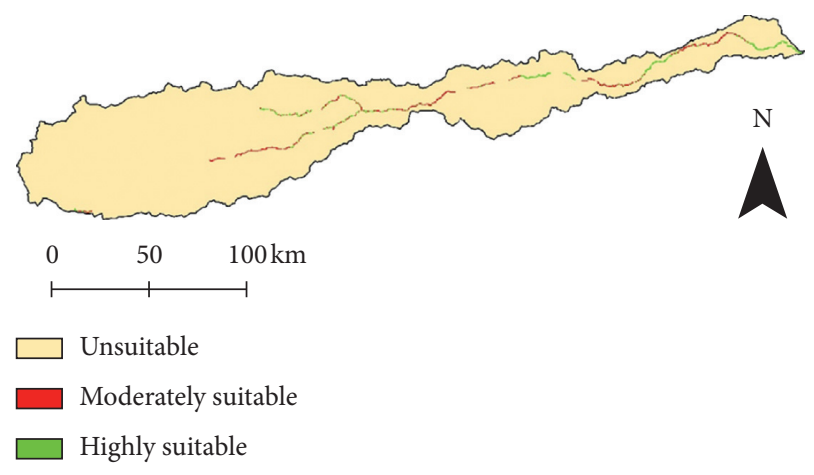

Figure 9: Map of suitable sites for rainwater harvesting.

\section{Conclusion}

It is very hard to revitalize a region that has a high probability of suffering from partial or total desertification. Therefore, it is more efficient and economical to protect the land before its degradation and minimize the negative impacts of desertification. This can be done in several ways, including by maintaining water resources, exporting these resources, and using technologically advanced methods to protect them from total loss.

This study has concentrated on the usage of RS with GIS to minimize desertification in the western desert of Iraq, with a consideration of the existent soil degradation condition and estimated possibility sites for RWH. The outcomes show that the changes in LDI with extreme, strong, and moderate degradations increased by $9 \%, 63 \%$, and $27 \%$, respectively, for the period 1999 to 2013. In addition, significant change of NDVI covered $6,981 \mathrm{~km}^{2}$, that is, $82 \%$ of the total study area, while the areas with a marginal change of NDVI was $1,532 \mathrm{~km}^{2}$ ( $18 \%$ of the whole study area). The rate of deterioration in the vegetation cover reached $18 \%$ in less than 15 years. The results of the combined rainwater harvesting suitability map and the maps of vegetation and degradation changes found that $65 \%$ of highly suitable sites are in areas with a large change of NDVI, and $35 \%$ of highly suitable sites are in areas with a small change of NDVI, while $90 \%$ of moderately suitable sites are in areas with large change of NDVI and $10 \%$ of moderately suitable sites are in 
areas with small change of NDVI. Moreover, $85 \%$ of highly suitable sites are in areas with a moderate change LDI, $12 \%$ of highly suitable sites are in areas with a strong change, and only $3 \%$ of highly suitable sites are in areas with no change.

The appropriateness map is beneficial to decisionmakers, and hydrologists for a quick reference and determination of the potential risk of desertification, as well as the identification of a proper sites for RWH to minimize the risk of desertification. The proposed method is effective in terms of time and cost, particularly for extent study areas where data availability is scarce. Validation of this approach was proved using the nature and characteristics of the study area.

\section{Data Availability}

Data are included within the mansucript.

\section{Conflicts of Interest}

The authors declare that they have no conflicts of interest.

\section{Authors' Contributions}

KNS, SOS, NA, AHK, NSM, and JA were responsible for conceptualization, KNS, SOS, NA, AHK, NSM, and JA were involved in data curation; KNS, SOS, NA, AHK, NSM, and JA helped in formal analysis; KNS, SOS, NA, AHK, NSM, and JA investigated the study; KNS, SOS, NA, AHK, NSM, and JA provided the methodology; NA carried out project administration; KNS, SOS, NA, AHK, NSM, and JA contributed resources; KNS, SOS, NA, AHK, NSM, and JA validated the study, KNS, SOS, NA, AHK, NSM, and JA were responsible for visualization; KNS, SOS, NA, AHK, NSM, and JA wrote the original draft, KNS, SOS, NA, AHK, NSM, and JA reviewed and edited the manuscript. All authors have read and agreed to the published version of the manuscript.

\section{References}

[1] N. Zeng and J. Yoon, "Expansion of the world's deserts due to vegetation-albedo feedback under global warming," Geophysical Research Letters, vol. 36, no. 17, Article ID L17401, 2009.

[2] W. C. Futrell, "UN conference on environment and development," in Green Politics: An A-to-Z Guide, SAGE Publications, Inc., Thousand Oaks, CA, USA, 1992.

[3] M. d'Angelo, G. Enne, S. Madrau, and L. Percich, "Mitigating land degradation in mediterranean agro-silvo-pastoral systems: a GIS-based approach," Catena, vol. 40, no. 1, pp. 37-49, 2000.

[4] United nations convention to combat desertification in those countries experiencing serious drought and/or desertification, particularly in africa, UN, p. 1 v. (various pagings), 1994.

[5] S. O. Sulaiman, N. Al-Ansari, A. Shahadha, R. Ismaeel, and S. Mohammad, "Evaluation of sediment transport empirical equations: case study of the Euphrates River West Iraq," Arabian Journal of Geosciences, vol. 14, no. 10, pp. 1-11, 2021.

[6] J. C. Katyal and P. L. G. Vlek, "Desertification: concept, causes and amelioration," Bonn, vol. 33, 2000.

[7] J. P. Chauzy and G. Appave, "Communicating effectively about migration, IOM World migration report," in Reporting At the Southern Borders: Journalism and Public Debates On
Immigration In the U.S. and the E.U, Routledge Studies in Global Information, London, UK, 2012.

[8] N. Al-Ansari, M. Ezz-Aldeen, S. Knutsson, and S. Zakaria, "Water harvesting and reservoir optimization in selected areas of south sinjar mountain, Iraq," Journal of Hydrologic Engineering, vol. 18, no. 12, pp. 1607-1616, 2013.

[9] S. O. Sulaiman, A. H. Kamel, K. N. Sayl, and M. Y. Alfadhel, "Water resources management and sustainability over the western desert of Iraq," Environmental Earth Sciences, vol. 78, no. 16, p. 495, 2019.

[10] A. Agarwal and S. Narain, "Making water management everybody's Business: water harvesting and rural development in India," Gatekeeper Ser., no. 87, International Institute for Environmental and Development, London, UK, 1999.

[11] S. Kolekar, S. Chauhan, H. Raavi, D. Gupta, and V. Chauhan, "Site selection of water conservation measures by using RS and GIS: a review," Advances in Computational Sciences and Technology, vol. 10, no. 5, pp. 805-813, 2017.

[12] K. N. Sayl, N. S. Muhammad, Z. M. Yaseen, and A. El-shafie, "Estimation the physical variables of rainwater harvesting system using integrated GIS-based remote sensing approach," Water Resources Management, vol. 30, no. 9, pp. 3299-3313, 2016.

[13] S. O. Sulaiman, G. Al-Dulaimi, and H. Al Thamiry, "Natural rivers longitudinal dispersion coefficient simulation using hybrid soft computing model," in Proceedings of the 2018 11th International Conference on Developments in eSystems Engineering (DeSE), pp. 280-283, Cambridge, UK, September 2018.

[14] M. Mekonnen, A. M. Melesse, and S. D. Keesstra, "Spatial runoff estimation and mapping of potential water harvesting sites: a GIS and remote sensing perspective, northwest Ethiopia," in Landscape Dynamics, Soils And Hydrological Processes in Varied Climates, A. M. Melesse and W. Abtew, Eds., Springer Geography, Springer International Publishing, Berlin, Germany, 2016.

[15] K. N. Sayl, N. S. Muhammad, and A. El-Shafie, "Robust approach for optimal positioning and ranking potential rainwater harvesting structure (RWH): a case study of Iraq," Arabian Journal of Geosciences, vol. 10, no. 18, Article ID 413, 2017.

[16] A. B. A. Najm, I. M. Abdulhameed, and S. O. Sulaiman, "Water requirements of crops under various kc coefficient approaches by using water evaluation and planning (WEAP)," International Journal of Design \& Nature and Ecodynamics, vol. 15, no. 5, pp. 739-748, 2020.

[17] M. G. Kumar, A. K. Agarwal, and R. Bali, "Delineation of potential sites for water harvesting structures using remote sensing and GIS," Journal of the Indian Society of Remote Sensing, vol. 36, no. 4, pp. 323-334, 2008.

[18] A. S. Mustafa, S. O. Sulaiman, and O. M. Hussein, “Application of SWAT model for sediment loads from valleys transmitted to haditha reservoir," Journal of Engineering, vol. 22, no. 1, pp. 184-197, 2016.

[19] A. K. Kadam, S. S. Kale, N. N. Pande, N. J. Pawar, and R. N. Sankhua, "Identifying potential rainwater harvesting sites of a semi-arid, basaltic region of western India, using SCS-CN method," Water Resources Management, vol. 26, no. 9, pp. 2537-2554, 2012.

[20] A. Adham, K. N. Sayl, R. Abed et al., "A GIS-based approach for identifying potential sites for harvesting rainwater in the western desert of Iraq," International Soil and Water Conservation Research, vol. 6, no. 4, pp. 297-304, 2018. 
[21] K. Sayl, A. Adham, and C. J. Ritsema, "A GIS-based multicriteria analysis in modeling optimum sites for rainwater harvesting," Hydrology, vol. 7, no. 3, Article ID 51, 2020.

[22] A. Ammar, M. Riksen, M. Ouessar, and C. Ritsema, "Identification of suitable sites for rainwater harvesting structures in arid and semi-arid regions: a review," International Soil and Water Conservation Research, vol. 4, no. 2, pp. 108-120, 2016.

[23] A. Pandey, V. M. Chowdary, B. C. Mal, and P. P. Dabral, "Remote sensing and GIS for identification of suitable sites for soil and water conservation structures," Land Degradation \& Development, vol. 22, no. 3, pp. 359-372, 2011.

[24] K. N. Sayl, N. S. Muhammad, and A. El-Shafie, "Optimization of area-volume-elevation curve using GIS-SRTM method for rainwater harvesting in arid areas," Environmental Earth Sciences, vol. 76, no. 10, p. 368, 2017.

[25] G. Modica, F. Solano, A. Merlino et al., "Using landsat 8 imagery in detecting cork oak (Quercus suber L.) woodlands: a case study in Calabria (Italy)," Journal of Agricultural Engineering, vol. 47, no. 4, pp. 205-215, 2016.

[26] E. Ozelkan, G. Chen, and B. B. Ustundag, "Multiscale objectbased drought monitoring and comparison in rainfed and irrigated agriculture from Landsat 8 OLI imagery," International Journal of Applied Earth Observation and Geoinformation, vol. 44, pp. 159-170, 2016.

[27] V. Soufflet, D. Tanré, A. Begue, A. Podaire, and P. Y. Deschamps, "Atmospheric effects on NOAA AVHRR data over Sahelian regions," International Journal of Remote Sensing, vol. 12, no. 6, pp. 1189-1203, 1991.

[28] J. R. G. Townshend and C. O. Justice, "Spatial variability of images and the monitoring of changes in the normalized difference vegetation index," International Journal of Remote Sensing, vol. 16, no. 12, pp. 2187-2195, 1995.

[29] J. M. Paruelo, M. F. Garbulsky, J. P. Guerschman, and E. G. Jobbágy, "Two decades of normalized difference vegetation index changes in South America: identifying the imprint of global change," International Journal of Remote Sensing, vol. 25, no. 14, pp. 2793-2806, 2004.

[30] Z. Wan, P. Wang, and X. Li, "Using MODIS land surface temperature and normalized difference vegetation index products for monitoring drought in the southern great plains, USA," International Journal of Remote Sensing, vol. 25, no. 1, pp. 61-72, 2004.

[31] V. K. Boken and C. F. Shaykewich, "Improving an operational wheat yield model using phenological phase-based normalized difference vegetation Index," International Journal of Remote Sensing, vol. 23, no. 20, pp. 4155-4168, 2002.

[32] R. Becerril-Piña, C. Díaz-Delgado, C. A. Mastachi-Loza, and E. González-Sosa, "Integration of remote sensing techniques for monitoring desertification in Mexico," Human and Ecological Risk Assessment: An International Journal, vol. 22, no. 6, pp. 1323-1340, 2016.

[33] J. Tomasella, R. M. Silva Pinto Vieira, A. A. Barbosa, D. A. Rodriguez, M. d. Oliveira Santana, and M. F. Sestini, "Desertification trends in the northeast of Brazil over the period 2000-2016," International Journal of Applied Earth Observation and Geoinformation, vol. 73, pp. 197-206, 2018.

[34] M. Dagnachew, A. Kebede, A. Moges, and A. Abebe, "Effects of climate variability on normalized difference vegetation index (NDVI) in the Gojeb river catchment, omo-gibe basin, Ethiopia," Advances in Meteorology, vol. 2020, p. 16, 2020.

[35] X. Zhang, Y. Yamaguchi, F. Li, B. He, and Y. Chen, "Assessing the impacts of the 2009/2010 drought on vegetation indices, normalized difference water index, and land surface temperature in southwestern China," Advances in Meteorology, vol. 2017, p. 9, 2017.

[36] J. Wright, T. M. Lillesand, and R. W. Kiefer, "Remote sensing and image interpretation," The Geographical Journal, vol. 146, no. 3, pp. 448-449, 1980.

[37] Y. Yue, M. Li, A.-x. Zhu et al., "Land degradation monitoring in the ordos plateau of China using an expert knowledge and BP-ANN-Based approach," Sustainability, vol. 8, no. 11, Article ID 1174, 2016.

[38] A. M. Fadhil, "Land degradation detection using geo-information technology for some sites in Iraq," J. Al-Journal of AlNahrain University Science, vol. 12, no. 3, pp. 94-108, 2009.

[39] R. Halbac-Cotoara-Zamfir, D. Smiraglia, G. Quaranta, R. Salvia, L. Salvati, and A. Giménez-Morera, "Land degradation and mitigation policies in the mediterranean region: a brief commentary," Sustainability, vol. 12, no. 20, Article ID $8313,2020$.

[40] B. Meng, J. Ge, T. Liang et al., "Evaluation of remote sensing inversion error for the above-ground biomass of alpine meadow grassland based on multi-source satellite data," Remote Sensing, vol. 9, no. 4, Article ID 372, 2017.

[41] J. Malczewski, "GIS-based land-use suitability analysis: a critical overview," Progress in Planning, vol. 62, no. 1, pp. 3-65, 2004.

[42] D. I. Heywood, S. C. Cornelius, and S. J. Carver, An Introduction to Geographical Information Systems, Pearson Prentice Hall, London, UK, 2011.

[43] J. R. Eastman, Idrisi for Windows: User's Guide: Version 2.0, Clark University, Department of Geography, Worcester, MA, USA, 1997.

[44] A. Yalcin, "GIS-based landslide susceptibility mapping using analytical hierarchy process and bivariate statistics in Ardesen (Turkey): comparisons of results and confirmations," Catena, vol. 72, no. 1, pp. 1-12, 2008.

[45] S. M. J. Baban and K. Wan-Yusof, "Modelling optimum sites for locating reservoirs in tropical environments," Water Resources Management, vol. 17, no. 1, pp. 1-17, 2003.

[46] R. Al-Adamat, A. Diabat, and G. Shatnawi, "Combining GIS with multicriteria decision making for siting water harvesting ponds in northern Jordan," Journal of Arid Environments, vol. 74, no. 11, pp. 1471-1477, 2010.

[47] H. Q. Hashim and K. N. Sayl, "Detection of suitable sites for rainwater harvesting planning in an arid region using geographic information system," Applied Geomatics, vol. 13, no. 2, pp. 235-248, 2020.

[48] K. N. Sayl, A. S. Mohammed, and A. D. Ahmed, "GIS-based approach for rainwater harvesting site selection," IOP Conference Series: Materials Science and Engineering, vol. 737, no. 1, Article ID 012246, 2020.

[49] M. A. Khudhair, K. N. Sayl, and Y. Darama, "Locating site selection for rainwater harvesting structure using remote sensing and GIS," IOP Conference Series: Materials Science and Engineering, vol. 881, no. 1, Article ID 012170, 2020.

[50] R. Al-Adamat, S. Al-Ayyash, H. Al-Amoush et al., "The combination of indigenous knowledge and geo-informatics for water harvesting siting in the jordanian badia," Journal of Geographic Information System, vol. 4, no. 4, pp. 366-376, 2012.

[51] V. K. Rana and T. M. V. Suryanarayana, "GIS-based multi criteria decision making method to identify potential runoff storage zones within watershed," Annals of GIS, vol. 26, no. 2, pp. 149-168, 2020.

[52] K. N. Sayl, N. S. Muhammad, and A. El-Shafie, "Identification of potential sites for runoff water harvesting," Proceedings of 
the Institution of Civil Engineers-Water Management, vol. 172, no. 3, pp. 135-148, 2019.

[53] A. S. Muneer, K. N. Sayl, and A. H. Kamel, "Modeling of runoff in the arid regions using remote sensing and geographic information system (GIS)," International Journal of Design \& Nature and Ecodynamics, vol. 15, no. 5, pp. 691-700, 2020.

[54] H. Q. Hashim and K. N. Sayl, "The application of radial basis network model, GIS, and spectral reflectance band recognition for runoff calculation," International Journal of Design \& Nature and Ecodynamics, vol. 15, no. 3, pp. 441-447, 2020.

[55] A. M. Melesse and S. F. Shih, "Spatially distributed storm runoff depth estimation using Landsat images and GIS," Computers and Electronics in Agriculture, vol. 37, no. 1-3, pp. 173-183, 2002.

[56] J. Krois and A. Schulte, "GIS-based multi-criteria evaluation to identify potential sites for soil and water conservation techniques in the ronquillo watershed, northern Peru," Applied Geography, vol. 51, pp. 131-142, 2014.

[57] W. Critchley, K. Siegert, and C. Chapman, Water Harvesting, FAO, Rome, Italy, 1991, https://www.fao.org/docrep/U3160E/ u3160e00.HTM.

[58] B. P. Mbilinyi, S. D. Tumbo, H. F. Mahoo, and F. O. Mkiramwinyi, "GIS-based decision support system for identifying potential sites for rainwater harvesting," Physics and Chemistry of the Earth, Parts $A / B / C$, vol. 32, no. 15-18, pp. 1074-1081, 2007.

[59] J. M. Kahinda, E. S. B. Lillie, A. E. Taigbenu, M. Taute, and R. J. Boroto, "Developing suitability maps for rainwater harvesting in South Africa," Physics and Chemistry of the Earth, Parts $A / B / C$, vol. 33, no. 8-13, pp. 788-799, 2008.

[60] I. A. Alwan, N. A. Aziz, and M. N. Hamoodi, "Potential water harvesting sites identification using spatial multi-criteria evaluation in Maysan province, Iraq," ISPRS International Journal of Geo-Information, vol. 9, no. 4, Article ID 235, 2020. 